\title{
Tarbes Nord (canton de)
}

Frédéric Guédon

URL : http://journals.openedition.org/adlfi/10788

ISSN : 2114-0502

Éditeur

Ministère de la culture

\section{Référence électronique}

Frédéric Guédon, «Tarbes Nord (canton de) », ADLFI. Archéologie de la France - Informations [En ligne], Midi-Pyrénées, mis en ligne le 01 mars 1997, consulté le 03 mai 2019. URL : http:// journals.openedition.org/adlfi/10788

Ce document a été généré automatiquement le 3 mai 2019.

(C) Ministère de la Culture et de la Communication, CNRS 


\title{
Tarbes Nord (canton de)
}

\author{
Frédéric Guédon
}

Date de l'opération : 1991 (PR)

Inventeur(s) : Guedon Frédéric

1 A partir d'un mémoire de Maîtrise portant sur l'occupation du sol au Moyen Âge et sur la base de sources écrites (Pouillès des diocèses de Tarbes et d'Auch, puis des provinces d'Auch, de Toulouse et de Narbonne), complétées par des prospections au sol, plusieurs gisements antiques (dont quelques-uns sont inédits) ont pu être répertoriés et, pour certains autres, réactualisés sur le plan chronologique.

Des établissements gallo-romains (tegulae, sigillées, céramiques communes et traces de murs) dont la nature reste indéterminée, sont signalés à Aureilhan, Lespieta ; Bordèressur-l'Échez, Cantillac (Gallia, 1968 : 551) ; Bours, Pradet ; Gayan, La Poutgette ; Oursbelille, Saint-Martin ; et sont associés à une occupation médiévale marquée par la présence de céramiques modelées difficilement datables.

Dans le cimetière d'Aurensan, une forte densité de vestiges médiévaux suggère l'emplacement du village ecclésial, alors qu'une motte castrale (diamètre de $28 \mathrm{~m}$, pour une hauteur d'environ $5 \mathrm{~m}$ ) entourée d'un fossé ( $7 \mathrm{~m}$ de large) est encore visible à Chis, Saint-Ferréol.

4 Au nord d'Oursbelille, une motte castrale (diamètre de $40 \mathrm{~m}$, pour une hauteur de 13 à $14 \mathrm{~m}$ ) est surmontée d'une tour circulaire (diamètre de $8 \mathrm{~m}$ environ) conservée sur $10 \mathrm{~m}$ de hauteur, pouvant être datée du $\mathrm{XIV}^{\mathrm{e}} \mathrm{s}$. mais qui est bâtie sur un édifice antérieur. L'ensemble est établi dans une vaste basse-cour trapézoïdale (7800 $\mathrm{m}^{2}$ environ) qui comporte encore les vestiges d'un mur d'enceinte.

5 Enfin, à Tarateix, Lasbordes, ont pu être détectés dans une cave, les vestiges du château $\mathrm{du}$ village mentionné encore en 1766 et sur la carte de Cassini. Des travaux d'aménagement dans la cour ont permis également de découvrir des sépultures en terre libre et un sarcophage du Bas Moyen Âge. 
INDEX

Index chronologique : Antiquité romaine, Moyen Âge*

Index géographique : Midi-Pyrénées, Hautes-Pyrénées (65), Tarbes

operation Prospection (PR) 